\title{
Autonomy Support: Explaining the Path from Leadership to Employee Creative Performance
}

\author{
Zakaria Hocine, Jian Zhang \\ Dongling School of Economics \& Management, University of Science and Technology, Beijing, China \\ Email: zakaria.hocine@gmail.com, zhangj67@manage.ustb.edu.cn
}

Received 11 April 2014; revised 17 May 2014; accepted 24 May 2014

Copyright (C) 2014 by authors and Scientific Research Publishing Inc. This work is licensed under the Creative Commons Attribution International License (CC BY). http://creativecommons.org/licenses/by/4.0/ c) (7) Open Access

\section{Abstract}

Today leaders are more like employee supporters than employee supervisors. Creating intentionally supportive and motivating environment, demonstrating concern for employees' well being, providing opportunities for autonomy support, avoiding rewards that actually decrease motivation and performance in the workplace for employee to be creative and innovative is part of modern leadership. The aim of the present paper is to provide a deeper understanding of how autonomy-supportive leadership fosters positive employee outcomes by taking employee innate needs into consideration. For this purpose, self-determination theory (SDT) fits best for its consideration of both social context (i.e., autonomy-supportive leadership) and individuals' basic psychological needs (i.e., autonomy, competence, and relatedness) as antecedents of motivation and well-being. In addition, we will give leaders some implications and discuss the importance of providing autonomy support, making sure of having the supportive environments required, and explain a clear path from leadership to employee positive behavior.

\section{Keywords}

Leadership, Autonomy Support, Individual Differences, Motivation, Creative Performance

\section{Introduction}

Literally thousands of management studies have been devoted to autonomy issues in organizations, places autonomy in the forefront of research on leadership and the management of employees [1]. Although followers' needs are a central aspect of leadership theories, nowadays, leaders face the challenges of motivating their followers. Psychological empowerment is one of the best tools to provide them felling of autonomy support and positive behavior. Empirical evidence suggests supportive-leadership as a model that could contribute to overcoming many of the leadership challenges faced by today's leaders.

Previous research materials have explored perceived organizational support, perceived supervisor support, 
and emphasized the relationship between supervisors' and employees' benefits on the basis of Social Exchange Theory (support-reward), which is an extrinsic motivation. This kind of empowerment mechanism is completely different from the new trend in the research of motivation. Deci and Ryan's self-determination theory considers that autonomy support is a kind of intrinsic motivation, because it is innate and comes from the self and that all behaviors driven by rewards are supposed to increase the employees' extrinsic motivation that by the end affects their creativity.

The present paper investigates the relationship between autonomy-supportive leadership behaviors and employees' creative performance and its effectiveness. It explains the path of impact of autonomy support on leadership and employee's creative performance.

\section{Leadership and Creative Performance}

Researcher suggested that leadership was the ability to influence those you are leading towards the achievement of goals and objectives [2]. Leadership is a function of management that ensures that desired results are achieved within an organization. It is the leadership that coordinates, guides, and directs efforts and activities in an organization or in this case a group toward achieving the set performance goals and objectives. An effective leader always inspires followers to desire to complete their tasks and motivates them to do more and better [3]. Yet, there are many leadership styles in the literature that authors have advocated over the past, from leader traits and qualities to modern leader theories suggest a supportive-leadership as a model that could contribute to overcoming many of the leadership challenges faced by today's leaders.

Employee creativity is a vital foundation for enterprises to gain competitive advantage and to capture competitive opportunities, and one key contextual factor that influences employee creativity is leadership. According to the componential theory of creativity, motivation is the primary mechanism by which the perceived work environment affects creativity [4]. Many leadership styles suffer from short-term motivation, ineffectiveness with unskilled labors, and ignorance of interpersonal relationships, which produce negative impact on performance. Research has found evidence of direct effects of leader behavior on subordinate perceptual reactions, affective reactions, and performance. Even tough, many researchers proved that supportive leadership behavior is positively correlated with employee creative performance [5]-[9].

People are most creative when they feel motivated by the interest, satisfaction and the challenge of the work itself and not by external pressures (extrinsic motivation) [10]. Task motivation, refers to individuals' attitudes toward a task and their perceptions of their own motivation for working on the task. Motivation can be either intrinsic (i.e., arising from individual's interest, involvement, curiosity, or satisfaction) or extrinsic (i.e., arising from sources outside of the task itself) in nature [11].

Social psychology research on creative performance had fully discussed the meaning and the process of the impact of environment on the individual creativity, and highlighted the impact of interpersonal environment on employee's creative performance manifested as manager's support of employees, and colleagues' relationships. Previous studies on job satisfaction, absenteeism, organizational trust, and loyalty, job performance and subjective wellbeing as dependent variables had discussed autonomy-supportive behavior effectiveness. Researchers proved that when subordinates perceive managers autonomy support, they would exhibit high job satisfaction, lower absenteeism, and better physical and mental state [12]. Pajak and Glickman found that manager's autonomy support inspires followers trust and loyalty [13]. Thus, focuses of managers on autonomy support had effectively aroused employees' creative performance.

Sahl and Koser found a negative correlation between managers controlling behavior and its R\&D department in charge of creativity of scientists. George and Zhou have found that supervisor's controlling behavior was negatively correlated with employee creativity. Researchers found that under restrictions and control conditions of individuals at doing a task, and reduction of autonomy, the creativity will also be reduced [14]. Zhou proved that supervisor's controlling behavior is negatively correlated with employee creativity [15]. Frese et al., have proved that the more supervisors are encouraging their employees, the more employees demonstrate new ideas and views to organizational creativity [16].

Christina et al., pointed out that most of the previous studies that provided supportive leadership styles were positively correlated with creativity. Amabile has found that supportive leadership style and controlling leadership style influence on employee creativity were different. Supportive leadership style promoted creativity, but controlling leadership style undermined it. When employee experiences supportive, developmental and informa- 
tional evaluation from his supervisor, he will be able to promote intrinsic motivation and helps himself to stimulate creativity [4].

\section{Autonomy Support}

Although previously much of the research on peak performance, via autonomy support, has been undertaken in the sport and education environments, recently organization and leadership support has been described as autonomy supportive, as this can involve providing choice, encouragement for personal initiatives and support for employee's competence, in a climate of relatedness [17].

Having autonomy is very important to employees. People have a strong need to control their lives and to participate in making decisions that affect them. Research found that autonomy was related to higher levels of job satisfaction and commitment and fewer thoughts of quitting. In environments of supporting leaders understand that their job is to create conditions where people thrive, not to control their every move. Providing supportive autonomy means giving people the room they need to succeed on their own, but also remaining hands-on enough to provide support when it is needed. Leaders create a positive workplace when they view their role as coordinating, facilitating, and supporting the work of their people rather than controlling it and pointed out some question, such as: Would your team members say that you provide them with supportive autonomy? Do they view you as someone who is available when they need help achieving their goals?

Research in other domains provides a deeper understanding of how autonomy-supportive behaviors affected volunteer motivation by taking volunteer individual differences into account. For this purpose, self-determination theory (SDT) utilized because this conceptual framework considers both the social context (i.e., autonomy-supportive) and individual differences (i.e., causality orientations) as antecedents of employee motivation. Causality orientations alter the way individuals perceive their social context as either autonomy-supportive or controlling (i.e., autonomy orientation or control orientation, respectively). Therefore, it is hypothesized that both types of causality orientations serve as moderators of the relationship between autonomy-supportive behaviors and volunteer perception of autonomy support.

Previously, Edward Deci has prescribed four behaviors of leaders: High control (HC), moderate control (MC), moderate autonomy support (MA), and high autonomy support (HA). Deci used a scale including the four kinds of solutions to leaders to choose the appropriate one in order to distinguish their behaviors (e.g. Kim is a working staff for several years. He is working with colleagues. In recent weeks, however, he is always preoccupied and listless. He is doing his work with less energy than usual. Being Kim's supervisor, the most appropriate way to: put pressure on him and ask him to increase his job rhythm is an important moderate control (MC); ask him and help him to come up with his listless is considered high autonomy (HA); warning him that if he keeps slow working rhythm, he will assume that some punitive measures are high control (HC); let him make a comparison on work efficiency with other colleagues which is a moderate autonomy (MA).

Amabile has found seven kinds of leadership behaviors that have significant effects on employee's perceived support through the work diary. Namely 1) Supporting—Positive; 2) Monitoring—Positive; 3) Recognizing_ Positive; 4) Consulting—Positive; 5) Clarifying Roles and Objectives; 6) Monitoring—Negative and 7) Problem Solving-Negative [4].

\section{Motivation}

Nowadays, leadership is more and more concerned with motivation. Motivation can be either intrinsic (i.e., arising from individual's interest, involvement, curiosity, or satisfaction) or extrinsic (i.e., arising from sources outside of the task itself) in nature [11]. Motivation is a psychological process that begins with a need that transforms into a positive behavior. According to [18] motivation is the mechanism by which a tightly organized goal hierarchy is created and controlled. Motivation controls attention, the ordering or the goal hierarchy, the criteria for determining when a goal is complete (satisfising, impatience) and which can be applied to each of the goals associated with the behavior (multifaceted criteria).

Maslow and Herzberg have been the pioneers in providing a conceptual framework of motivation. However, the concept is still evolving with other concepts, we draw on Edward L. Deci and Richard M. Ryan theory, two of the authors, whom have developed a theory of human motivation over the past 30 years, called self-determination theory, (SDT; [19] which can be regarded as one of the most detailed and best validated framework of human needs [20] to explore followers' needs. SDT identifies the core principles underlying sustainable motivation [19] 
[21] [22]. Also, central to SDT is the distinction between autonomous motivation and controlled motivation.

Many researchers mentioned the three types of motivation namely; intrinsic motivation, extrinsic motivation and amotivation [19] [23] [24] [25]. These three types of motivation also affect performance in various ways. Extrinsic motivation refers to behaviors aiming at attain a reward or benefit, rather than for the enjoyment of activity itself [26]. Extrinsic motivation comprises three types of motivation [22]. External regulation, introjection and identified regulation. Intrinsic motivation refers to a person's engagement in an activity for the pleasure of achieving internally defined goals. Amotivation is characterized by the absence of both extrinsic and intrinsic motivation and refers to a person's disability to manage the demands of the activity and feels amotivated. Extrinsic motivation most controlled is external regulation. Introjection represents a somewhat more autonomous form of external motivation. The most self-determined type of it is identified regulation. Intrinsic motivation is highly form of autonomous motivation. Amotivation is a non-self-determined form of motivation.

According to SDT, humans have three basic psychological needs: autonomy, competence, and relatedness [22]. Autonomy concerns the experience of acting with a sense of choice, volition, and self-determination. Competence is the belief that one has the ability to influence important outcomes. Relatedness is the experience of having satisfying and supportive social relationships. It is only when these needs are met then the employees are fully motivated. Supportive work environment and workplace settings lead to the satisfaction of the psychological needs of competence, relatedness, and autonomy. It encourages the intrinsic motivation and promotes the full internalization of the extrinsic motivation, which all together promotes autonomous motivation, which is a form of intrinsic motivation. Whereas, controlling work environments diminish employees' experiences of autonomy, competence, and relatedness. They create "external" and "introjected" regulations. Self-determination theory posits that under autonomy-supportive conditions, people internalize the value of doing activities that are not initially interesting. A study by [27] supported this proposal, demonstrating that when people are provided with a rationale for doing a task, when their feelings toward the task are acknowledged and when they are given some choice about how to do it, they come to internalize the value of doing it. Self-determination theory is not only concerned with understanding the nature and consequences of autonomy, but also in detailing how autonomy develops, and how it can be either diminished or facilitated by social conditions, such as workplaces and leadership influence [28].

Thus, SDT proposed six step processes for autonomy supportiveness to introduce autonomous motivations by: (1) asking open questions and invite participation in problem solving; (2) actively listen and acknowledge employee perspectives; (3) offering choice with structure and clarify the responsibilities; (4) providing sincere, positive feedback that acknowledges initiative and factual, non-judgmental feedback about problems; (5) minimizing coercive controls such as rewards and comparisons with others, and (6) developing talent and share knowledge to enhance competence and autonomy.

\section{Discussion and Recommendations}

The concept of leadership and autonomy support has lacked attention. Nowadays organizations suffer from poor supervision, poor interpersonal relationships, poor working conditions, and lack of healthy work conditions, which as explained by Sager is a hindrance to employee motivation. From the articles discussed above it is felt that organizations should use modern concepts in management and apply new form of vision statements to communicate a more effective guidance for the employees. The role of leadership should be enlarged. The leaders should ensure needs of their followers to perceive autonomy support. Autonomy support should be a big motivating factor in organizations. Hence, that is not the only solution. The leaders are recommended to empower their employees for better results. They should focus on building good relationship with employees as well as paying attention to the task. The sense of lack of job healthy environment should be eliminated and the old motivation tradition should be abandoned. Most importantly, leaders should take their followers' perspective in setting goals and carrying out jobs. Not only this will increase their morale, reduce fear, but also impact a sense of belongingness to their organization. No matter the leadership style is, a leader must adjust his leadership approach according to the needs and the motivations of his followers. Leaders should provide them felling of autonomy support and self-determination, and let them respond with renewed energy, psychological empowerment, and motivation when they are working for leaders who are perceived as caring about others as unique individuals. The old adage that "people do not care what you know until they know that you care" suggests the importance of individual consideration. Hence, all leaders should care for their employees, listen with intention, rather 


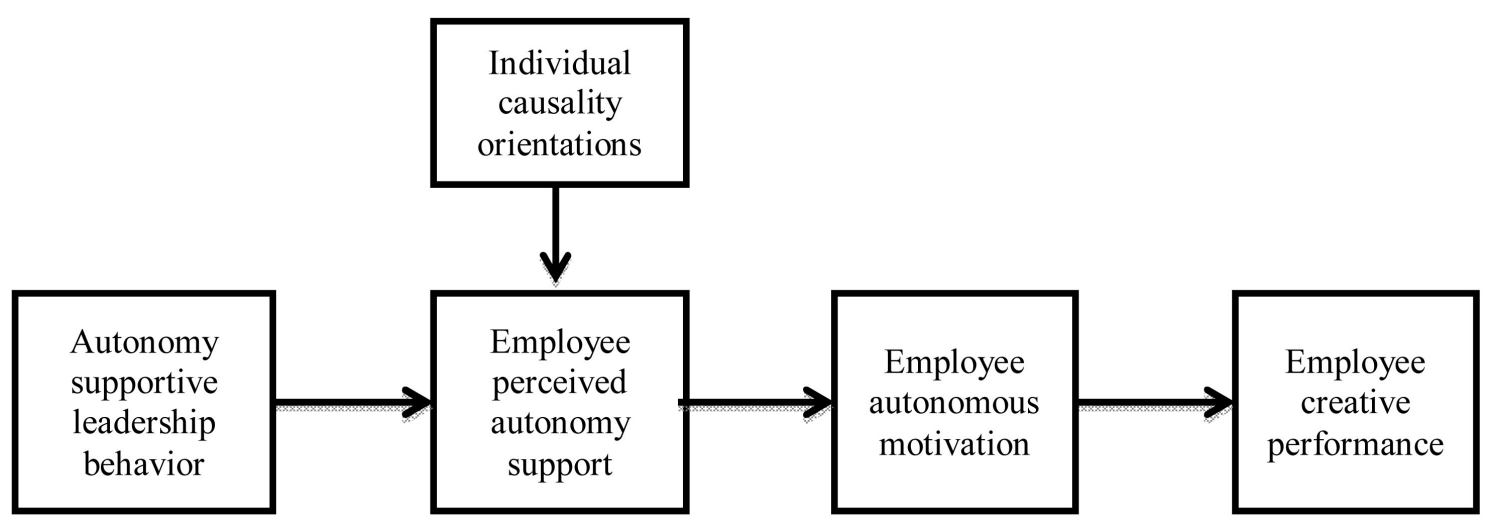

Figure 1. Study path model.

than hear with filters. Instead of dictating the right answers, the leaders should facilitate solutions with the right questions and balance action with reflection. They should recognize and acknowledge the talents of their followers.

By summing up the literature, we found that autonomy support plays a crucial role respectively with self-determination theory orientations. Thus, leaders have to expect from the integration of autonomy-supportive methods plenty of positive outcomes of followers. This suggests that Autonomy-Supportiveness should be part of Signature's leadership development program, but how? Is it even possible for leaders to learn to be more Autonomy-Supportive of their staff, or is it simply something leaders are born with? The good news is that there is a mountain of evidence that leaders can learn to become more Autonomy-Supportive.

At present, leaders autonomy-supportive behavior specific content is basically in a blank state; the measurement scale of autonomy-supportive leadership is relatively scarce. Generally, researchers use PAS scale that enumerates some management practices scenarios; and research on manager's support is mainly based on the theory of social exchange. Therefore the study on the relationship between the two variables needs more empirical evidence and content. The mechanism of the influence of autonomy-supportive leadership behavior on follower positive behavior needs more interventions. Perhaps, it is not necessarily for autonomy-supportive leaders to expect performance only from intrinsically motivated employees, they should get through other intervening conditions, such as individual general causality orientations, perceived autonomy support, employees basic psychological needs satisfaction, autonomous motivation and finally get to creative performance. Besides, the research has to discuss the independent role of autonomy support on motivation and prediction of creative performance among employees. In essence, from the point of view of autonomous motivation, we can recognize factors that affect employee's creative performance.

In addition, the present work recommends Self-determination theory as a theoretical framework to define autonomy-supportive leadership behavior specific contents, and exploring its effectiveness as well as paths of impact. It offers the opportunity to ground the complex social phenomenon of leadership and followership in positive psychology. Also, it explores the mechanisms of autonomy-supportive leadership and creative performance of employees, which may reveal practical advice for leadership and management.

Hence, the discussion provides an important path for this study in term of the process that is going to be used. Figure 1 illustrates the conceptual framework of this study. Finally, the idea of autonomy support rings true, and it is highly recommended to test it within the organizational context to see how it produces superior results when someone is autonomously motivated.

\section{Acknowledgements}

We especially thank the National Science Foundation of China (70771009, 71071017) and the Fundamental Research Funds for the Central Universities (FRF-BR-09-019) for supporting this research.

\section{References}

[1] Gagné, M. and Bhave, D. (2011) Autonomy in the Workplace: An Essential Ingredient to Employee Engagement and Well-Being in Every Culture. In: Chirkov, V.I., Ryan, R.M. and Sheldon, K.M., Eds., Human Autonomy in Cross- 
Cultural Context: Perspectives on the Psychology of Agency, Freedom, and Well-Being, Springer, Dordrecht, 163-187. http://dx.doi.org/10.1007/978-90-481-9667-8_8

[2] Bass, B.M. (1990) Bass \& Stogdill’s Handbook of Leadership; Theory, Research, and Managerial Applications. 3rd Edition, The Free Press, New York.

[3] Schultz, H. and Gordon, J. (2011) Onward: How Starbucks Fought for Its Life without Losing Its Soul. Rodale.

[4] Amabile, T.M., Schatzel, E.A., Moneta, G.B. and Kramer, S.J. (2004) Leader Behaviors and the Work Environment for Creativity: Perceived Leader Support. The Leadership Quarterly, 15, 5-32. http://dx.doi.org/10.1016/j.leaqua.2003.12.003

[5] Blais, M.R. and Brie Re, N.M. (1992) On the Mediational Role of Feelings of Self-Determination in the Workplace: Further Evidence and Generalization. Manuscript, University of Quebec at Montreal, Montreal.

[6] Stahl, M.J. and Koser, M.C. (1978) Weighted Productivity in R\&D: Some Associated Individual and Organizational Variables. Transactions on Engineering Management, 25, 20-24. http://dx.doi.org/10.1109/TEM.1978.6447271

[7] George, M. and Zhou, J. (2001) When Openness to Experience and Conscientiousness Are Related to Creative Behavior: An Interactional Approach. Journal of Applied Psychology, 86, 513-524. http://dx.doi.org/10.1037/0021-9010.86.3.513

[8] Zhou, J. (2003) When the Presence of Creative Coworkers Is Related to Creativity: Role of Supervisor Close Monitoring, Developmental Feedback, and Creative Personality. Journal of Applied Psychology, 88, 413-422. http://dx.doi.org/10.1037/0021-9010.88.3.413

[9] Christinna, E., Shalley, Zhou, J., et al. (2004) The Effects of Personal and Contextual Characteristics on Creativity: Where Should We Go from Here? Journal of Management, 6, 933-958.

[10] Amabile, T.M. (1996) Creativity in Context. Westview, Boulder.

[11] Amabile, T.M. (1988) A Model of Creativity and Innovation in Organizations. In: Staw, B.M. and Cummings, L.L., Eds., Research on Organizational Behavior, JAI Press, Greenwich, 123-167.

[12] Vallerand, R.J., Pelletier, L.G., Blais, M.R., Briere, N.M., Senecal, C. and Valliéres, E.F. (1992) The Academic Motivation Scale: A Measure of Intrinsic, Extrinsic, and Amotivation in Education. Educational and Psychological Measurement, 52, 1003-1017. http://dx.doi.org/10.1177/0013164492052004025

[13] Pajak, E. and Glickman, C. (1989) Informational and Controlling Language Insimulated Supervisory Conferences. American Educational Research Journal, 26, 93-106. http://dx.doi.org/10.3102/00028312026001093

[14] Zhou, J. and George, J.M. (2001) When Job Dissatisfaction Leads to Creativity: Encouraging the Expression of Voice. Academy of Management Journal, 44, 682-696. http://dx.doi.org/10.2307/3069410

[15] Zhou, J. and Shalley, C.E. (2008) Handbook of Organizational Creativity. Lawrence Erlbaum, Hillsdale.

[16] Frese, M. and Zapf, D. (1999) On the Importance of the Objective Environment in Stress and Attribution Theory. Counterpoint to Perrewé and Zellars. Journal of Organizational Behavior, 20, 761-765. http://dx.doi.org/10.1002/(SICI)1099-1379(199909)20:5<761::AID-JOB951>3.0.CO;2-Y

[17] Deci, E.L., Ryan, R.M., Gagne, M., Leone, D., Usunov, J. and Kornazheva, B.P. (2001) Need Satisfaction, Motivation, and Well-Being in the Work Organizations of a Former Eastern Bloc Country. Personality and Social Psychology Bulletin, 27, 930-942. http://dx.doi.org/10.1177/0146167201278002

[18] Simon H. (1967) Motivational and Emotional Controls of Cognition. Psychological Review, 74, 29-39. http://dx.doi.org/10.1037/h0024127

[19] Deci, E.L. and Ryan, R.M. (1985) Intrinsic Motivation and Self-Determination in Human Behavior. Plenum, New York. http://dx.doi.org/10.1007/978-1-4899-2271-7

[20] Kovjanic, S., Schuh, S.C., Jonas, K., Van Quaquebeke, N. and Van Dick, R. (2012) How Do Transformational Leaders Foster Positive Employee Outcomes? A Self-Determination-Based Analysis of Employees’ Needs as Mediating Links. Journal of Organizational Behavior, 33, 1031-1052. http://dx.doi.org/10.1002/job.1771

[21] Ryan, R.M. and Deci, E.L. (2007) Active Human Nature: Self-Determination Theory and the Promotion and Maintenance of Sport, Exercise, and Health. In: Hagger, M.S. and Chatzisarantis, N.L.D., Eds., Intrinsic Motivation and SelfDetermination in Exercise and Sport, Human Kinetics, Champaign, 1-19.

[22] Deci, E.L. and Ryan, R.M. (2000) The "What” and the "Why” of Goal Pursuits: Human Needs and the Self-Determination of Behavior. Psychological Inquiry, 11, 227-268. http://dx.doi.org/10.1207/S15327965PLI1104_01

[23] Deci, E.L. (1975) Intrinsic Motivation. Plenum Publishing Co., New York. http://dx.doi.org/10.1007/978-1-4613-4446-9

[24] Deci, E.L. and Ryan, R.M. (1987) The Support of Autonomy and the Control of Behavior. Journal of Personality and Social Psychology, 53, 1024-1037. http://dx.doi.org/10.1037/0022-3514.53.6.1024 
[25] Vallerand, R.J. and Losier, G.F. (1999) An Integrative Analysis of Intrinsic and Extrinsic Motivation in Sport. Journal of Applied Sport Psychology, 11, 142-169. http://dx.doi.org/10.1080/10413209908402956

[26] Deci, E.L. (1971) Effects of Externally Mediated Rewards on Intrinsic Motivation. Journal of Personality and Social Psychology, 18, 105-115. http://dx.doi.org/10.1037/h0030644

[27] Deci, E.L., Eghrari, H., Patrick, B.C. and Leone, D. (1994) Facilitating Internalization: The Self-Determination Theory Perspective. Journal of Personality, 62, 119-142. http://dx.doi.org/10.1111/j.1467-6494.1994.tb00797.x

[28] Gagné, M. and Deci, E.L. (2005) Self-Determination Theory and Work Motivation. Journal of Organizational Behavior, 26, 331-362. http://dx.doi.org/10.1002/job.322 